\title{
PRÁTICAS CORPORAIS, COMPORTAMENTO DESVIANTE E CONSUMO DE ÁLCOOL E DROGAS: uma revisão sistemática
}

\author{
Priscilla Pinto Costa da Silva ${ }^{1}$ \\ Giuliano Gomes Pimentel2 \\ Cheng Hsin Nery Chao 3
}

\begin{abstract}
RESUMO
O estudo objetiva revisar na literatura científica acerca das práticas corporais e o consumo de álcool e drogas a partir do comportamento desviante. Trata-se de uma revisão sistemática nas bases de dados MEDLINE, Scielo, Scopus, Web of Science e SportDiscus, utilizando os descritores e palavras-chave "lazer desviante", "sociologia do desvio", "práticas corporais", "álcool" e "drogas". Os critérios de inclusão foram artigos originais, estudos publicados em periódicos nacionais e internacionais. Vinte estudos publicados em periódicos foram analisados minuciosamente. Os estudos encontrados foram organizados em categorias de acordo com a temática trabalhada: i) lazer, práticas corporais e comportamento desviante em adolescentes e adultos; ii) práticas corporais e comportamento desviante no âmbito do trabalho, e iii) práticas corporais e comportamento desviante em diferentes grupos. As práticas corporais foram vistas como aspecto que podem auxiliar na prevenção de uso de álcool e drogas, mas que sejam direcionadas as formas de prevenção.
\end{abstract}

Palavras-chave: Atividades de lazer. Drogas. Álcool. Terapias complementares

1 Doutora pela Universidade de Pernambuco (UPE). Departamento de Educação Física/Universidade Federal do Rio Grande do Norte (UFRN). Natal/ Rio Grande do Norte, Brasil E-mail: laprisci@gmail.com

2 Doutor pela Universidade Estadual de Campinas (UNICAMP). Departamento de Educação Física/Universidade Estadual de Maringá (UEM). Maringá/ Paraná, Brasil. E-mail: ggapimentel@uem.br

3 Doutor pela Universidade Federal do Rio Grande do Norte (UFRN). Departamento de Educação Física/ Universidade Federal do Rio Grande do Norte (UFRN). Natal/ Rio Grande do Norte, Brasil.

E-mail: nerychao@gmail.com 


\title{
BODY PRACTICES, DEVIANT BEHAVIOR AND ALCOHOL AND DRUG
} CONSUMPTION: a systematic review

\begin{abstract}
The study aims to review in the scientific literature about the corporal practices and the consumption of alcohol and drugs from the deviant behavior. It is a systematic review in the MEDLINE, Scielo, Scopus, Web of Science and SportDiscus databases, using the descriptors and keywords "deviant leisure", "deviant sociology", "corporal practices", "alcohol" and "drugs". The inclusion criteria were original articles, studies published in national and international journals. Twenty studies published in journals were analyzed in detail. The studies were organized in categories according to the theme: i) leisure, body practices and deviant behavior in adolescents and adults; ii) body practices and deviant behavior in the work area; and iii) corporal practices and deviant behavior in different groups. The body practices were seen as aspect that can aid in the prevention of alcohol and drug use, but that are directed the forms of prevention.
\end{abstract}

Keywords: Leisure activities. Drug. Alcohol. Complementary therapies

\section{PRÁCTICAS CORPORALES, EL COMPORTAMIENTO DESVIADO Y CONSUMO DE ALCOHOL Y DROGAS: una revisión sistemática}

\section{RESUMEN}

El estudio del objetivo es revisar la literatura científica sobre las prácticas corporales y el consumo de alcohol y drogas de la conducta desviada. Se trata de una revisión sistemática en MEDLINE, SciELO, Scopus, Web of Science y SportDiscus utilizando descriptores y palabras clave "ocio desviada", "sociología de la desviación", "prácticas corporales", "alcohol" y "drogas". Los criterios de inclusión fueron artículos originales, estudios publicados en revistas nacionales e internacionales. Se analizaron veinte estudios publicados en revistas. Los estudios encontrados fueron organizados en categorías de acuerdo con la temática trabajado: i) el ocio, las prácticas corporales y la conducta desviada en adolescentes y adultos; ii) el cuerpo y prácticas desviadas en el trabajo, y iii) las prácticas corporales y la conducta desviada en diferentes grupos. Las prácticas corporales fueron vistos como un aspecto que puede ayudar en la prevención de alcohol y drogas, pero que las formas de prevención se dirigen.

Palabras clave: Actividades de ocio. Drogas. Alcohol. Terapias complementarias 


\section{INTRODUÇÃO}

Na Modernidade há diversificação dos estilos de vida associados ao lazer. Todavia nem todos eles são socialmente julgados como adequados, o que reverbera no número crescente de pessoas que infringem regras sociais e são tidas como desviantes (BECKER 2008; ELIAS 2000). Por esse entendimento, o usuário excessivo de álcool e drogas ilícitas, por fugir das normas sociais e poder desencadear um comportamento de risco à saúde, é compreendido como desviante.

Becker (2008) aponta esse comportamento como uma "carreira desviante", pois as razões pelas quais uma pessoa consume bebida alcoólica, por exemplo, pela primeira vez, podem diferir das razões em que esta pessoa torna-se um consumidor ocasional ou até mesmo consumidor regular de bebida alcoólica. $\mathrm{O}$ autor apresenta uma abordagem sequencial para o consumo sociocultural de drogas, a partir de dois eixos: a aprendizagem gradual sobre os efeitos da droga durante a transição da iniciação ao uso ocasional, até o uso regular. Peretti-Watel e Lorente (2004) ressaltam que a experimentação aparece a partir da curiosidade e a oportunidade, após isso, os usuários aprendem onde e como adquirir e usar as drogas com segurança.

Diante desse contexto, as práticas corporais e o uso de drogas vêm sendo alvo de várias estratégias educacionais para prevenção de comportamento desviante (PERETTI-WATEL; LORENTE, 2004). O sistema de trabalho na saúde mental está sendo transformado em um modelo orientado a recuperação, em que há ênfase na vida ativa (IWASAKI; COYLE; SHANK, 2010). O Programa Segundo Tempo, é um exemplo de prevenção por meio das práticas corporais, em que um dos objetivos específicos condiz na contribuição em diminuir a exposição de riscos sociais, como o uso de drogas (BRASIL, 2011).

No entanto, a visão generalista das práticas corporais enquanto estilo de vida saudável e prevenção ao uso excessivo do álcool e das drogas ilícitas, como expõe Romera (2009; 2013; 2014), torna-se simplista. De forma mecânica, as práticas corporais estão inseridas diretamente no contexto de estilo de vida saudável, além da prevenção aos comportamentos e condutas de risco. Assim, classificar as práticas corporais sob uma única dimensão de estilo de vida saudável é enganoso. Bourdieu (2013) ressalta que não existe um estilo de vida certo ou errado, mas estilos de vida que a sociedade impõe enquanto referência para determinados grupos, envolvendo saúde, educação, economia, política, religião e outras áreas. Esta relação de certo e errado, também defendida por Elias e Scotson (2000, p.8) como estabelecidos e outsiders ou desviantes "se definem na relação que as nega e que as constitui como identidades sociais" destacando a relação de poder existente nos quadros sociais e rotulando sujeitos de um grupo social. Assim, o desvio ou anormalidade tem como significado o status de exclusão, sendo ainda entendido como o diferente (WANDERLEY, 1999).

Desta forma, vale destacar a importância do uso do tempo livre, pois há diferentes formas de utilizar esse tempo, como exemplo, a prática de atividades estruturantes, como o esporte orientado, e atividades desestruturadas, como assistir televisão (MAHONEY; STATTIN, 2000). Contudo, algumas formas de lazer estão relacionadas ao comportamento 
desviante, como o consumo do álcool excessivo e o consumo de drogas. Mahoney e Stattin (2000), quando se referem a adolescentes, apontam que as oportunidades para envolver-se em comportamentos desviantes são maiores durante as atividades de lazer não estruturadas, quando comparadas àquelas que são muito estruturadas. Os autores ainda colocam que essa estrutura e o contexto social apresentam conceitos distintos, mas pode haver relações entre os dois aspectos, uma vez que a complexidade social envolve o apoio da família e orientação de adultos, por exemplo.

Ahn et al. (2014) apontam que a prevenção do crime pode ser desenvolvida por meio das práticas corporais e lazer, pois essas práticas podem ser uma alternativa de prevenção. Além disso, Korhonen et al. (2009) em um estudo de caráter epidemiológico apontam que a inatividade física em adolescentes pode desencadear fatores que aumente o comportamento desviante na fase adulta, principalmente referente ao consumo excessivo de álcool e drogas ilícitas. No caso dos idosos, estudos (AHN et al., 2014; YI et al., 2005) realizados a partir do comportamento desviante revelam que à prática do lazer podem aliviar os problemas sociopsicológicos nessa faixa etária. É importante frisar o estudo de Coelho e Pérez-Ramos (2008), no qual os autores discutiram a reabilitação relacionada ao redimensionamento dos objetivos pessoais e das formas de enfrentar situações de risco como mecanismo para abstinência e para a redução de danos.

Por outro lado, estudos internacionais (PERETTI-WATEL, 2003; PERETTI-WATEL; LORENTE 2004) apontam a relação entre as práticas corporais e uso das drogas depende de fatores como o tipo de prática, gênero e idade. Referente ao Brasil, pesquisas (ROMERO, 2006; PALMA; ABREU; CUNHA, 2007) com ênfase na ligação entre práticas corporais e uso de álcool e drogas, vêm apresentando resultados inconsistentes no que diz respeito à prevenção ao comportamento de risco, indicando que tanto em adolescentes (ROMERO, 2006), como em jovens e adultos (PALMA; ABREU; CUNHA, 2007) a prevalência de consumo de álcool e drogas e práticas corporais são significativas tanto no sexo masculino como no feminino.

Assim, o presente estudo seguiu o questionamento: Como as práticas corporais e o comportamento desviante, referente ao consumo de álcool e drogas, são apresentados na literatura científica? O objetivo do estudo é revisar na literatura científica acerca das práticas corporais e o consumo de álcool e drogas a partir do comportamento desviante.

\section{Procedimento metodológico}

Trata-se de uma revisão sistemática, pois permite integrar relações de um conjunto de estudos aplicando determinados métodos para sistematizar resultados semelhantes ou contrários, seguindo de avaliações que determinam a qualidade e validade do estudo, além de aproximar temas relevantes para estudos futuros (WRIGHT et al, 2007; MULROW, 1994). Para a escolha da revisão sistemática e seleção dos estudos foram seguidas, de forma adaptada, as orientações propostas por Gomes e Caminha (2014): identificação da necessidade da revisão, preparação da proposta a ser estudada, seleção das bases de 
dados, dos descritores e dos estudos, organização dos dados, avaliação da qualidade dos estudos, extração, síntese e interpretação dos dados e a redação do texto final.

Assim, as bases de dados eletrônicas selecionadas para o estudo foram MEDLINE, Scielo, Scopus, Web of Science e SportDiscus utilizando os descritores e palavras-chave "deviant leisure", "sociology of deviance", "alcohol" e "drugs". Foram utilizados os termos operantes and e not na busca dos artigos para combinar os descritores e palavras-chave. Estes termos foram selecionados por serem pertinentes ao tema estudado.

Como critérios de inclusão, foram adotados artigos originais, estudos publicados em periódicos nacionais e internacionais, publicados entre 1990 a 2016 e artigos pertinentes à temática estudada e que estejam disponíveis nos periódicos CAPES. Os critérios de exclusão foram artigos de revisão de literatura, ensaios, resenhas, monografias, dissertações e teses. Para a seleção dos estudos foi realizada a análise baseada nos títulos dos artigos selecionados. A etapa seguinte consistiuem examinar dos resumos, objetivando selecionar estudos relacionados à temática, e no terceiro momento, os artigos selecionados foram lidos na íntegra. Após essa etapa, realizou-se uma busca pelo autor principal dos artigos selecionados na tentativa de localizar pesquisas que atendessem aos critérios de inclusão. Vale ressaltar que a seleção foi realizada por doi revisores independentes, utilizando um formulários adotando os critérios de inclusão e os de exclusão estabelecidos. Os artigos que não houve consenso quanto aos critérios, foram apreciados por um terceiro revisor.

Para apreciar as informações coletadas, foi utilizada a análise de conteúdo, aplicando a técnica análise categorial recomendada por Bardin (2002). As informações coletadas foram examinadas e organizadas a partir de um formulário com os seguintes elementos: autor/ ano, objetivo, descritores utilizados, procedimentos metodológicos, e principais achados.

\section{Resultados e discussão}

No primeiro momento foram encontrados 1376 artigos relacionados à temática estudada, sendo MedLine (1233), Scielo (8), Scopus (53), Web of Science (53) e SportDiscus (29). Foi realizada a leitura dos títulos de todos os artigos encontrados. Em seguida, os resumos dos textos selecionados foram lidos atentamente. Após essa leitura, 24 artigos foram selecionados. Posteriormente, procedeu-se a leitura dos textos na integra, selecionando 17 artigos. A partir dos artigos selecionados, foi realizada uma busca pelos nomes dos autores dos artigos, encontrando mais três textos relacionados à temática, totalizando 20 estudos.

Os estudos selecionados foram organizados no quadro 1, apresentado a seguir, destacando as principais características dos estudos. 
Quadro 1: Síntese dos estudos sobre práticas corporais, lazer desviante e uso de álcool e drogas

\begin{tabular}{|c|c|c|c|c|}
\hline Autor/Ano & Objetivos & $\begin{array}{l}\text { Descritores/ } \\
\text { palavras-chave }\end{array}$ & $\begin{array}{l}\text { Procedimento } \\
\text { metodológico }\end{array}$ & Principais achados \\
\hline $\begin{array}{l}\text { Thorlindsson; } \\
\text { Vilhjalmsson; } \\
\text { valgeirsson } \\
\text { (1990) }\end{array}$ & $\begin{array}{l}\text { Lançar luz sobre } \\
\text { a relação entre } \\
\text { participação esporte } \\
\text { e saúde percebida } \\
\text { por estimar os efeitos } \\
\text { diretos de participação } \\
\text { desportiva, bem como } \\
\text { seus efeitos indiretos que } \\
\text { são mediadas por: (1) } \\
\text { outros comportamentos } \\
\text { relacionados com a } \\
\text { saúde, no caso de } \\
\text { fumar e o uso de } \\
\text { álcool, (2) desconfortos } \\
\text { psicológicos sob a } \\
\text { forma de ansiedade, } \\
\text { depressão e sintomas } \\
\text { psicofisiológica. Analisar } \\
\text { as consequências } \\
\text { da participação } \\
\text { desportiva para a } \\
\text { depressão, ansiedade e } \\
\text { psicofisiológica sintomas } \\
\text { para a população } \\
\text { adolescente. }\end{array}$ & $\begin{array}{l}\text { Esporte } \\
\text { participação, } \\
\text { saúde percebida, } \\
\text { efeito direto, } \\
\text { efeito indireto. }\end{array}$ & $\begin{array}{l}\text { Estudo transversal. } \\
1200 \text { adolescentes } \\
\text { islandeses, com } \\
\text { idade entre } 15 \text { e } \\
16 \text { anos, do gênero } \\
\text { masculino e feminino, } \\
\text { responderam um } \\
\text { questionário. }\end{array}$ & $\begin{array}{l}\text { A participação desportiva tem } \\
\text { um efeito direto significativo } \\
\text { sobre a saúde percebida, } \\
\text { controlando outros } \\
\text { aspectos relacionados ao } \\
\text { comportamento, sofrimento } \\
\text { psíquico e estado da doença. } \\
\text { A participação esportiva } \\
\text { também afeta a saúde } \\
\text { percebida indiretamente por } \\
\text { meio de angústia e de fumar, } \\
\text { mas não parece funcionar } \\
\text { com o consumo de álcool. }\end{array}$ \\
\hline $\begin{array}{l}\text { Mahoney; } \\
\text { Stattin (2000) }\end{array}$ & $\begin{array}{l}\text { Entender como a } \\
\text { estrutura e o contexto } \\
\text { social de atividades de } \\
\text { lazer em adolescentes } \\
\text { relacionado com } \\
\text { o comportamento } \\
\text { antissocial. }\end{array}$ & Não informado. & $\begin{array}{l}\text { Estudo transversal. } \\
703 \text { jovens ( } 351 \\
\text { meninos, } 352 \\
\text { meninas) de } 14 \\
\text { anos e seus pais } \\
\text { de Örebro/Suécia, } \\
\text { responderam um } \\
\text { questionário referente } \\
\text { a participação } \\
\text { do adolescente } \\
\text { em atividades de } \\
\text { lazer comunitárias, } \\
\text { e adultos nas } \\
\text { relações sociais e } \\
\text { comportamento } \\
\text { antissocial. }\end{array}$ & $\begin{array}{l}\text { Os resultados mostraram } \\
\text { que a participação em } \\
\text { atividades de lazer } \\
\text { altamente estruturados foi } \\
\text { ligada a baixos níveis de } \\
\text { comportamento antissocial, } \\
\text { enquanto que a participação } \\
\text { em atividades com baixa } \\
\text { estrutura foi associada } \\
\text { com altos níveis de } \\
\text { comportamento antissocial. }\end{array}$ \\
\hline
\end{tabular}




\begin{tabular}{|c|c|c|c|c|}
\hline Autor/Ano & Objetivos & $\begin{array}{l}\text { Descritores/ } \\
\text { palavras-chave }\end{array}$ & $\begin{array}{l}\text { Procedimento } \\
\text { metodológico }\end{array}$ & Principais achados \\
\hline $\begin{array}{l}\text { Vazsonyi et } \\
\text { al. (2002) }\end{array}$ & $\begin{array}{l}\text { Analisar as semelhanças } \\
\text { entre países e as } \\
\text { diferenças de atividades } \\
\text { de rotina, medidas } \\
\text { de desvio e seu } \\
\text { relacionamento, em } \\
\text { adolescentes. }\end{array}$ & $\begin{array}{l}\text { Comportamento } \\
\text { desviante, } \\
\text { inadimplência, } \\
\text { atividades de } \\
\text { rotina, pesquisa } \\
\text { transcultural. }\end{array}$ & $\begin{array}{l}\text { Estudo transversal. } \\
7.000 \text { adolescentes do } \\
\text { gênero masculino e } \\
\text { feminino, com idade } \\
\text { entre } 15 \text { a } 19 \text { anos, } \\
\text { da Hungria, Holanda, } \\
\text { Suíça e Estados } \\
\text { Unidos, responderam } \\
\text { a um questionário. }\end{array}$ & $\begin{array}{l}\text { Para a maioria dos } \\
\text { adolescentes, a maior parte } \\
\text { de seu tempo foi gasto em } \\
\text { atividades solitárias, seguido } \\
\text { por atividades de pares, } \\
\text { comunidade/atividades } \\
\text { esportivas e atividades } \\
\text { familiares; Adolescentes } \\
\text { húngaros disseram gastar } \\
\text { uma quantidade muito maior } \\
\text { de tempo com a família do } \\
\text { que adolescentes rovenientes } \\
\text { de outros países, enquanto } \\
\text { adolescentes holandeses } \\
\text { passaram muito mais tempo } \\
\text { em atividades solitárias do } \\
\text { que seus pares. }\end{array}$ \\
\hline $\begin{array}{l}\text { Peretti-Watel; } \\
\text { Lorente } \\
(2004)\end{array}$ & $\begin{array}{l}\text { Estudar a relação entre o } \\
\text { uso de maconha, prática } \\
\text { de esportes e outras } \\
\text { atividades de lazer } \\
\text { durante a adolescência, } \\
\text { como um teste para } \\
\text { da teoria sociológica } \\
\text { de oportunidades } \\
\text { desviantes. }\end{array}$ & $\begin{array}{l}\text { Maconha, } \\
\text { adolescentes, } \\
\text { prática do } \\
\text { esporte, lazer, } \\
\text { oportunidades. }\end{array}$ & $\begin{array}{l}\text { Estudo survey } \\
\text { Uma amostra de } \\
12.512 \text { adolescentes } \\
\text { franceses com } \\
\text { idade média de } 18 \\
\text { anos respondeu um } \\
\text { questionário contendo } \\
\text { três modelos logísticos } \\
\text { (para uso ocasional, } \\
\text { recente e regular } \\
\text { da maconha) foram } \\
\text { estimados para as } \\
\text { meninas e os meninos } \\
\text { separadamente. }\end{array}$ & $\begin{array}{l}\text { Saídas e outras atividades } \\
\text { orientadas por pares foram } \\
\text { fortemente correlacionados } \\
\text { com o consumo de maconha, } \\
\text { mas esse relacionamento } \\
\text { dependia dos níveis de } \\
\text { utilização. O uso ocasional } \\
\text { foi mais comum entre os } \\
\text { sujeitos que participaram } \\
\text { de diferentes atividades } \\
\text { ao ar livre. O uso regular } \\
\text { foi associado a um estilo } \\
\text { de vida mais seletiva, com } \\
\text { foco em passeios e tempo } \\
\text { relacionados à música. }\end{array}$ \\
\hline $\begin{array}{l}\text { Thorlindsson; } \\
\text { Bemburg } \\
\text { (2006) }\end{array}$ & $\begin{array}{l}\text { Explorar as relações } \\
\text { entre as atividades de } \\
\text { lazer dos adolescentes, } \\
\text { o comportamento } \\
\text { dos colegas e uso de } \\
\text { substâncias. }\end{array}$ & Não informado. & $\begin{array}{l}\text { Estudo survey. } \\
7.785 \text { estudantes } \\
\text { islandeses, com idade } \\
\text { entre } 15 \text { e } 16 \text { anos, } \\
\text { responderam a um } \\
\text { questionário sobre } \\
\text { atividade de lazer } \\
\text { e comportamento } \\
\text { desviantes }\end{array}$ & $\begin{array}{l}\text { Os resultados mostram que } \\
\text { o álcool e uso de substâncias } \\
\text { varia significativamente entre } \\
\text { três padrões de lazer, esporte, } \\
\text { festa como estilo de vida, } \\
\text { e envolvimento em clubes } \\
\text { sociais. Além disso, verificou- } \\
\text { se que a conhecida relação } \\
\text { entre o uso de substâncias } \\
\text { na adolescência e ter amigos } \\
\text { que usam a substância } \\
\text { é significativamente } \\
\text { dependente do tipo de } \\
\text { padrão de lazer. }\end{array}$ \\
\hline
\end{tabular}




\begin{tabular}{|c|c|c|c|c|}
\hline Autor/Ano & Objetivos & $\begin{array}{l}\text { Descritores/ } \\
\text { palavras-chave }\end{array}$ & $\begin{array}{l}\text { Procedimento } \\
\text { metodológico }\end{array}$ & Principais achados \\
\hline $\begin{array}{l}\text { Frijins et al. } \\
(2010)\end{array}$ & $\begin{array}{l}\text { Examinar se a } \\
\text { divulgação e a pesquisa } \\
\text { podem ser distinguidas } \\
\text { como dois fatores } \\
\text { distintos dentro de } \\
\text { um questionário } \\
\text { de divulgação de } \\
\text { adolescente comumente } \\
\text { usado. }\end{array}$ & $\begin{array}{l}\text { Revelação, sigilo, } \\
\text { relação pais e } \\
\text { adolescentes, } \\
\text { ajuste do } \\
\text { adolescente. }\end{array}$ & $\begin{array}{l}\text { Estudo survey. } \\
309 \text { adolescentes } \\
\text { holandeses, sendo } \\
149 \text { do gênero } \\
\text { masculino e } 160 \\
\text { feminino, com } \\
\text { idade média de 13,2 } \\
\text { anos, responderam } \\
\text { questionários sobre } \\
\text { revelação e sigilo para } \\
\text { adolescentes. }\end{array}$ & $\begin{array}{l}\text { A análise fatorial confirmou } \\
\text { que a divulgação e sigilo } \\
\text { deve ser distinguidas como } \\
\text { duas construções separadas. } \\
\text { Além disso, apenas o sigilo } \\
\text { foi um preditor longitudinal } \\
\text { de internalização adolescente } \\
\text { (ex. a depressão) e problemas } \\
\text { de externalização (ex. a } \\
\text { delinquência). O Sigilo } \\
\text { consistentemente contribuiu } \\
\text { para a predição longitudinal } \\
\text { da delinquência desde } \\
\text { a média adolescência, } \\
\text { enquanto que contribuiu para } \\
\text { a predição da depressão só } \\
\text { no início da adolescência. }\end{array}$ \\
\hline $\begin{array}{l}\text { Keijsers et al. } \\
(2012)\end{array}$ & $\begin{array}{l}\text { Examinar como o } \\
\text { controle e proibição } \\
\text { dos pais na relação de } \\
\text { amizade referente à } \\
\text { influência indesejável } \\
\text { dos pares }\end{array}$ & Não informado. & $\begin{array}{l}\text { Estudo longitudinal. } \\
\text { Utilizou-se } \\
\text { questionários anuais } \\
\text { para } 497 \text { jovens } \\
\text { holandeses, seus } \\
\text { melhores amigos, e } \\
\text { ambos os pais (283 } \\
\text { meninos, idade média } \\
13 \text { anos). }\end{array}$ & $\begin{array}{l}\text { O relato dos pais aponta } \\
\text { que a proibição de amizade } \\
\text { previu positivamente } \\
\text { com os pares desviantes, } \\
\text { e indiretamente na } \\
\text { inadimplência dos } \\
\text { adolescentes. }\end{array}$ \\
\hline $\begin{array}{l}\text { Doktor-Jelölt } \\
\text { (2013) }\end{array}$ & $\begin{array}{l}\text { Descobrir as mudanças } \\
\text { ocorridas dentro de oito } \\
\text { anos na atividade de } \\
\text { tempo livre dos jovens } \\
\text { húngaros com idade } \\
\text { entre } 15 \text { a } 19 \text { anos. }\end{array}$ & $\begin{array}{l}\text { Atividade física, } \\
\text { tempo livre, } \\
\text { tabagismo. }\end{array}$ & $\begin{array}{l}\text { Estudo Transversal; } \\
\text { Duas pesquisas } \\
\text { realizadas pelo } \\
\text { Instituto Nacional } \\
\text { da Família e da } \\
\text { Política Social, a } \\
\text { Hungria em } 2000 \\
\text { e } 2008 \text {, incluindo } \\
1780 \text { e } 2018 \text { jovens, } \\
\text { respectivamente, } \\
\text { foram analisadas e } \\
\text { comparadas. }\end{array}$ & $\begin{array}{l}\text { O número de jovens } \\
\text { envolvidos em atividade } \\
\text { esportiva aumentou } \\
\text { significativamente, enquanto } \\
\text { que a sua média de consumo } \\
\text { não conseguiu diminuir. Os } \\
\text { jovens fisicamente ativos são } \\
\text { mais conscientes à saúde, } \\
\text { mas a atividade esportiva } \\
\text { regular não tenha descartado } \\
\text { o tabagismo. }\end{array}$ \\
\hline $\begin{array}{l}\text { Titzmann; } \\
\text { Silbereisen; } \\
\text { Mesch (2014) }\end{array}$ & $\begin{array}{l}\text { Investigar preditores } \\
\text { de níveis iniciais e } \\
\text { taxas de mudança } \\
\text { na delinquência de } \\
\text { imigrantes e nativos da } \\
\text { Alemanha }\end{array}$ & $\begin{array}{l}\text { Delinquência, } \\
\text { aculturação, a } \\
\text { imigração, a } \\
\text { adolescência. }\end{array}$ & $\begin{array}{l}\text { Estudo longitudinal. } \\
\text { Participaram } 607 \\
\text { adolescentes, do } \\
\text { gênero masculino, } \\
\text { com idade entre } 11 \text { a } \\
19 \text { anos, na Alemanha } \\
\text { e Israel, de } 2003 \text { a } \\
2006 \text {. }\end{array}$ & $\begin{array}{l}\text { Modelos de curvas de } \\
\text { crescimento mostrou que } \\
\text { adolescentes de etnia alemã } \\
\text { relataram níveis iniciais mais } \\
\text { elevados de inadimplência } \\
\text { do que adolescentes alemães } \\
\text { nativos e níveis mais baixos } \\
\text { do que os adolescentes } \\
\text { judeus russos. Os grupos não } \\
\text { diferiram na taxa de variação, } \\
\text { indicando uma diminuição } \\
\text { da inadimplência ao longo } \\
\text { do tempo. }\end{array}$ \\
\hline
\end{tabular}




\begin{tabular}{|c|c|c|c|c|}
\hline Autor/Ano & Objetivos & $\begin{array}{l}\text { Descritores/ } \\
\text { palavras-chave }\end{array}$ & $\begin{array}{l}\text { Procedimento } \\
\text { metodológico }\end{array}$ & Principais achados \\
\hline $\begin{array}{l}\text { Halldorsson; } \\
\text { Thorlindsson; } \\
\text { Sigfusdottir } \\
\text { (2014) }\end{array}$ & $\begin{array}{l}\text { Investiga a relação } \\
\text { entre a participação de } \\
\text { adolescente no esporte } \\
\text { e o uso do álcool, com } \\
\text { foco em diferenças nos } \\
\text { contextos desportivos. }\end{array}$ & $\begin{array}{l}\text { Uso de álcool, a } \\
\text { participação do } \\
\text { esporte, esporte } \\
\text { formal e informal, } \\
\text { influências } \\
\text { dos pais dos } \\
\text { adolescentes, } \\
\text { cultura de } \\
\text { pares, o } \\
\text { desenvolvimento } \\
\text { positivo, o } \\
\text { contexto social }\end{array}$ & $\begin{array}{l}\text { Estudo survey. } \\
10.992 \text { adolescentes } \\
\text { islandeses, com } \\
\text { idade entre } 13 \text { a } \\
16 \text { anos, do gênero } \\
\text { masculino e feminino, } \\
\text { responderam a um } \\
\text { questionário sobre a } \\
\text { temática. }\end{array}$ & $\begin{array}{l}\text { Os resultados indicam } \\
\text { que os adolescentes que } \\
\text { participam de clubes } \\
\text { desportivos formalmente } \\
\text { organizados são menos } \\
\text { propensos a usar o álcool } \\
\text { do que aqueles que não o } \\
\text { participam. Os resultados } \\
\text { obtidos para a participação } \\
\text { no desporto informal são no } \\
\text { sentido inverso, indicando } \\
\text { que os adolescentes que } \\
\text { fazem único esporte informal } \\
\text { são mais propensos a } \\
\text { usar o álcool. Além disso, } \\
\text { verificou-se que a relação } \\
\text { entre o consumo de álcool } \\
\text { por adolescente e ter amigos } \\
\text { que consomem álcool } \\
\text { depende da participação } \\
\text { formal esporte. Acredita-se } \\
\text { que a participação no esporte } \\
\text { formal é mais relevante para } \\
\text { os grupos de adolescentes } \\
\text { que estão em maior risco } \\
\text { para o uso de álcool, porque } \\
\text { armazenam os efeitos de } \\
\text { fatores de risco conhecidos } \\
\text { sobre o uso do álcool. A } \\
\text { participação no esporte } \\
\text { informal não significa, } \\
\text { contudo, tapar tais efeitos. }\end{array}$ \\
\hline Askew (2016) & $\begin{array}{l}\text { Explorar como os } \\
\text { adultos, usuários } \\
\text { de drogas, com fins } \\
\text { "recreativos" são } \\
\text { responsáveis por seu } \\
\text { consumo ilícito ao lado } \\
\text { de outras formas de vida. }\end{array}$ & $\begin{array}{l}\text { Uso de drogas } \\
\text { recreativas por } \\
\text { adulto, } \\
\text { Psicologia } \\
\text { discursiva, } \\
\text { Legitimação, } \\
\text { Neutralização, } \\
\text { Normalização }\end{array}$ & $\begin{array}{l}\text { Vinte e seis entrevistas } \\
\text { em profundidade } \\
\text { foram conduzidas } \\
\text { com indivíduos com } \\
\text { idades entre os } 30 \text { e } \\
\text { 59. Cada participante } \\
\text { tinha tomado drogas } \\
\text { no ano passado, } \\
\text { sua principal fonte } \\
\text { de renda não foi } \\
\text { um resultado de } \\
\text { atividade criminosa } \\
\text { e eles não estavam a } \\
\text { receber tratamento } \\
\text { medicamentoso. Foi } \\
\text { usada a Psicologia } \\
\text { Discursiva para } \\
\text { analisar como } \\
\text { os participantes } \\
\text { descrevem, razão e } \\
\text { justificar seu uso. }\end{array}$ & $\begin{array}{l}\text { A análise resultou no } \\
\text { desenvolvimento de três } \\
\text { enquadramentos discursivos } \\
\text { que demonstram as } \\
\text { diferentes formas em que } \\
\text { o uso de drogas ilícitas } \\
\text { pode ser legitimado. O } \\
\text { quadro "culturas de drogas" } \\
\text { destaca o acesso às drogas } \\
\text { nas redes sociais. O quadro } \\
\text { "celebração planejada" } \\
\text { que descreve a frequência } \\
\text { ocasional de uso de drogas } \\
\text { para legitimar o consumo. } \\
\text { O quadro "oportunidade } \\
\text { situacional" que se } \\
\text { posiciona no amplo acesso } \\
\text { e disponibilidade de drogas } \\
\text { como a influência do seu } \\
\text { comportamento. }\end{array}$ \\
\hline
\end{tabular}


maio/2018

\begin{tabular}{|c|c|c|c|c|}
\hline Autor/Ano & Objetivos & $\begin{array}{l}\text { Descritores/ } \\
\text { palavras-chave }\end{array}$ & $\begin{array}{l}\text { Procedimento } \\
\text { metodológico }\end{array}$ & Principais achados \\
\hline $\begin{array}{l}\text { Liebregr et al. } \\
\text { (2015) }\end{array}$ & $\begin{array}{l}\text { Contribuir para a } \\
\text { literatura existente } \\
\text { sobre a normalização } \\
\text { e a relação entre o uso } \\
\text { frequente de maconha, } \\
\text { dependência e lazer. }\end{array}$ & $\begin{array}{l}\text { Trajetórias } \\
\text { de maconha; } \\
\text { dependência } \\
\text { da maconha; } \\
\text { métodos } \\
\text { qualitativos; } \\
\text { longitudinal; } \\
\text { lazer; } \\
\text { normalização }\end{array}$ & $\begin{array}{l}\text { Como parte de um } \\
\text { projeto longitudinal } \\
\text { de } 3 \text { anos, em um } \\
\text { estudo qualitativo, } \\
\text { com a participação } \\
\text { de } 47 \text { jovens adultos } \\
\text { do sexo masculino } \\
\text { e feminino e } \\
\text { consumidores de } \\
\text { cannabis com ( } \mathrm{n}= \\
\text { 23) e sem ( } \mathrm{n}=24) \\
\text { dependência, no } \\
\text { início do estudo foram } \\
\text { entrevistados em } \\
\text { profundidade, após } \\
\text { 1,5 e } 3 \text { anos. }\end{array}$ & $\begin{array}{l}\text { Os consumidores frequentes } \\
\text { de maconha (no início do } \\
\text { estudo, } \geq 3 \text { dias por semana } \\
\text { nos últimos } 12 \text { meses) estão } \\
\text { envolvidos em atividades de } \\
\text { lazer semelhantes, como a } \\
\text { população adulta jovem geral } \\
\text { e vivem uma vida bastante } \\
\text { convencional, geralmente } \\
\text { longe de uma subcultura } \\
\text { delinquente. A maioria } \\
\text { deles regula o seu consumo } \\
\text { de maconha ao tempo de } \\
\text { lazer, para melhorar outras } \\
\text { atividades de lazer, incluindo } \\
\text { a socialização e jogos de } \\
\text { vídeo. Enquanto que muitas } \\
\text { vezes dão prioridade às } \\
\text { responsabilidades (por } \\
\text { exemplo, trabalho e estudo), } \\
\text { os usuários dependentes e } \\
\text { não dependentes diferiam em } \\
\text { se adaptar ativamente as suas } \\
\text { atividades de lazer ao seu } \\
\text { consumo de maconha, ou o } \\
\text { seu consumo de maconha ao } \\
\text { seu tempo de lazer. Ambos } \\
\text { os tipos de tempo gasto em } \\
\text { atividades de lazer foram } \\
\text { associadas com transições em } \\
\text { uso e dependência. }\end{array}$ \\
\hline $\begin{array}{l}\text { Boylstein } \\
(2013)\end{array}$ & $\begin{array}{l}\text { Examinar o percurso } \\
\text { (início, meio e fim) da } \\
\text { carreira desviante da } \\
\text { rede de produção da } \\
\text { maconha. }\end{array}$ & $\begin{array}{l}\text { Qualitativa; } \\
\text { carreira } \\
\text { desviante; } \\
\text { maconha; lazer. }\end{array}$ & $\begin{array}{l}\text { Estudo etnográfico } \\
\text { combinando } \\
\text { observação } \\
\text { e entrevista } \\
\text { semiestruturada } \\
\text { durante } 6 \text { anos, na } \\
\text { região central da } \\
\text { Flórida. } \\
\text { Foram entrevistados } \\
8 \text { pessoas, sendo } 6 \\
\text { homens e } 2 \text { mulheres }\end{array}$ & $\begin{array}{l}\text { Descobriu-se que os } \\
\text { produtores de maconha } \\
\text { seguem um padrão } \\
\text { semelhante envolvido aos } \\
\text { aspectos de julgamento e } \\
\text { erro, mas que aprendem } \\
\text { novas técnicas para melhorar } \\
\text { seu produto, no que diz } \\
\text { respeito ao sabor, potência } \\
\text { e produção. A paixão pela } \\
\text { atividade é mais importante } \\
\text { que o dinheiro. A interrupção } \\
\text { da atividade é influenciada } \\
\text { pelas contingências como } \\
\text { o risco de detecção, } \\
\text { compromisso com a família e } \\
\text { ocupações convencionais. }\end{array}$ \\
\hline
\end{tabular}




\begin{tabular}{|c|c|c|c|c|}
\hline Autor/Ano & Objetivos & $\begin{array}{l}\text { Descritores/ } \\
\text { palavras-chave }\end{array}$ & $\begin{array}{l}\text { Procedimento } \\
\text { metodológico }\end{array}$ & Principais achados \\
\hline $\begin{array}{l}\text { Belhassem; } \\
\text { Shani (2013) }\end{array}$ & $\begin{array}{l}\text { Examinar a interação } \\
\text { entre alguns fatores } \\
\text { entre da cultura } \\
\text { organizacional, controle } \\
\text { social, alienação do } \\
\text { trabalho e estresse } \\
\text { relacionado com } \\
\text { o trabalho, e sua } \\
\text { influência sobre o uso de } \\
\text { substâncias psicoativas } \\
\text { em trabalhadores da } \\
\text { rede hoteleira. }\end{array}$ & $\begin{array}{l}\text { Comportamento } \\
\text { desviante, } \\
\text { tabagismo, } \\
\text { consumo } \\
\text { excessivo de } \\
\text { álcool, alienação } \\
\text { do trabalho, } \\
\text { satisfação no } \\
\text { trabalho. }\end{array}$ & $\begin{array}{l}\text { Estudo survey. } \\
458 \text { trabalhadores de } \\
\text { hotéis em Eilat/Israel } \\
\text { responderam aos } \\
\text { questionários Escala } \\
\text { de Satisfação no } \\
\text { Trabalho e Escala de } \\
\text { alienação. }\end{array}$ & $\begin{array}{l}\text { Os trabalhadores da } \\
\text { rede hoteleira usam mais } \\
\text { substâncias do que a } \\
\text { taxa média da população } \\
\text { israelense. Beber não está } \\
\text { ligada a atitudes negativas } \\
\text { em relação ao trabalho do } \\
\text { usuário. A prevalência de } \\
\text { fumar cigarro promove uma } \\
\text { cultura em que o do cigarro, } \\
\text { mesmo durante o horário de } \\
\text { trabalho, não se manifesta } \\
\text { necessariamente em uma } \\
\text { atitude negativa no trabalho. }\end{array}$ \\
\hline $\begin{array}{l}\text { Wood; Tirone } \\
\text { (2013) }\end{array}$ & $\begin{array}{l}\text { Mostrar como as } \\
\text { mulheres, os fatores } \\
\text { contextuais (cuidado, } \\
\text { envolvimento nocivo, } \\
\text { expectativas da } \\
\text { sociedade), as formas } \\
\text { de lazer influenciam à } \\
\text { saúde. }\end{array}$ & $\begin{array}{l}\text { Vício, cuidado, } \\
\text { família, lazer, } \\
\text { mulheres. }\end{array}$ & $\begin{array}{l}\text { Estudo exploratório. } \\
10 \text { mulheres que } \\
\text { trabalham cuidando } \\
\text { de pessoas envolvidas } \\
\text { álcool, drogas e jogos } \\
\text { de azar, responderam } \\
\text { a uma entrevista } \\
\text { semiestruturada. }\end{array}$ & $\begin{array}{l}\text { Três temas nortearam os } \\
\text { achados: perda de lazer, } \\
\text { negociação de lazer e o lazer } \\
\text { como fuga. Compreender } \\
\text { a experiência das mulheres } \\
\text { no âmbito do lazer no } \\
\text { sentido das relações do } \\
\text { cuidado conduz implicações } \\
\text { importantes para a saúde. }\end{array}$ \\
\hline $\begin{array}{l}\text { Engelberg; } \\
\text { Sjöberg } \\
(2004)\end{array}$ & $\begin{array}{l}\text { Investigar a extensão } \\
\text { em que as habilidades } \\
\text { interpessoais, } \\
\text { personalidade e } \\
\text { inteligência emocional } \\
\text { (IE) foram relacionados } \\
\text { com o grau de utilização } \\
\text { da Internet }\end{array}$ & Não informado. & $\begin{array}{l}\text { Estudo transversal. } \\
41 \text { universitários de } \\
\text { Estocolmo/Suécia, } \\
\text { com idade média de } \\
21,1 \text { anos de idade, } \\
\text { sendo } 20 \text { mulheres } \\
\text { e } 21 \text { homens, } \\
\text { responderam a Escala } \\
\text { de Dependência de } \\
\text { Internet. }\end{array}$ & $\begin{array}{l}\text { O uso da Internet está } \\
\text { relacionada à solidão } \\
\text { e adesão aos valores } \\
\text { idiossincráticos (efeitos } \\
\text { fortes), e também o mais } \\
\text { pobre equilíbrio entre } \\
\text { trabalho e lazer e inteligência } \\
\text { emocional (efeitos mais } \\
\text { fracos). Não foi encontrada } \\
\text { relação entre a personalidade } \\
\text { e o uso da Internet. Os } \\
\text { resultados sugerem que } \\
\text { os utilizadores frequentes } \\
\text { tendem a ser solitários, a ter } \\
\text { valores desviantes. }\end{array}$ \\
\hline $\begin{array}{l}\text { Belhassen et } \\
\text { al. (2007) }\end{array}$ & $\begin{array}{l}\text { Investigar as forças } \\
\text { sociais que moldam } \\
\text { motivações dos turistas } \\
\text { em consumir maconha } \\
\text { durante as férias. }\end{array}$ & $\begin{array}{l}\text { Maconha, a } \\
\text { motivação, a } \\
\text { normalização, } \\
\text { grounded theory. }\end{array}$ & $\begin{array}{l}\text { Grounded theory } \\
\text { a partir do estudo } \\
\text { etnográfico realizado } \\
\text { no Egito, Países } \\
\text { Baixos e Índia. Foram } \\
\text { entrevistados } 18 \\
\text { pessoas, sendo } 12 \\
\text { homens e } 6 \text { mulheres, } \\
\text { além da observação } \\
\text { dos turistas que } \\
\text { usavam maconha } \\
\text { durante a viagem. }\end{array}$ & $\begin{array}{l}\text { Foram identificados quatro } \\
\text { grupos de cúpula de } \\
\text { motivações para consumir } \\
\text { maconha durante a viagem: } \\
\text { a experimentação, prazer } \\
\text { e diversão, busca de } \\
\text { autenticidade, e compra } \\
\text { acessíveis. Cada categoria } \\
\text { é orientada e discutida, } \\
\text { respectivamente, em função } \\
\text { de quatro explicações } \\
\text { teóricas: afrouxamento } \\
\text { do controle social, o lazer } \\
\text { contínuo comportamental, } \\
\text { moldando e manifestação } \\
\text { da identidade social, e ao } \\
\text { contrabando como uma } \\
\text { carreira desviante. }\end{array}$ \\
\hline
\end{tabular}




\begin{tabular}{|c|c|c|c|c|}
\hline Autor/Ano & Objetivos & $\begin{array}{l}\text { Descritores/ } \\
\text { palavras-chave }\end{array}$ & $\begin{array}{l}\text { Procedimento } \\
\text { metodológico }\end{array}$ & Principais achados \\
\hline $\begin{array}{l}\text { Wynveen; } \\
\text { Bixler; } \\
\text { Hammitt } \\
\text { (2006) }\end{array}$ & $\begin{array}{l}\text { Identificar crimes } \\
\text { específicos que foram } \\
\text { percebidos pelos } \\
\text { guardas do parque } \\
\text { National Park Service. }\end{array}$ & Não informado. & $\begin{array}{l}\text { Estudo Survey. } \\
527 \text { pessoas, com } \\
\text { idade entre } 23 \text { a } 65 \\
\text { anos, responderam ao } \\
\text { questionário na Web. }\end{array}$ & $\begin{array}{l}\text { Os resultados indicaram } \\
\text { que a invasão urbana está } \\
\text { correlacionada com as } \\
\text { percepções do crime em uma } \\
\text { área de passatempo. Roubo, } \\
\text { incêndio, roubo de veículos, } \\
\text { homicídios e vandalismo } \\
\text { são crimes percebido que } \\
\text { ocorrem com mais frequência } \\
\text { nos parques mais próximos } \\
\text { das áreas urbanas. Em } \\
\text { contraste, a caça ilegal e } \\
\text { roubo de artefato foram } \\
\text { crimes significativos que } \\
\text { ocorrem com mais frequência } \\
\text { nos parques mais distantes } \\
\text { dos centros urbanos. }\end{array}$ \\
\hline $\begin{array}{l}\text { Taylor; Khan } \\
\text { (2011) }\end{array}$ & $\begin{array}{l}\text { Detalhar as perspectivas } \\
\text { de skatistas sobre } \\
\text { a utilidade e } \\
\text { funcionalidade de } \\
\text { parques de skate na } \\
\text { Austrália Ocidental. }\end{array}$ & Não informado. & $\begin{array}{l}\text { Método misto. } \\
34 \text { skatistas foram } \\
\text { entrevistados com } \\
\text { idade entre } 12 \text { a } 20 \\
\text { anos. }\end{array}$ & $\begin{array}{l}\text { O estudo revela que os } \\
\text { skatistas acreditam que os } \\
\text { adultos os veem como sendo } \\
\text { antissocial e a busca de lazer } \\
\text { na prática do skate como um } \\
\text { passatempo indesejável que } \\
\text { exige regulamentação. }\end{array}$ \\
\hline Cohen (2011) & $\begin{array}{l}\text { Examinar indivíduos } \\
\text { que optaram seu estilo } \\
\text { de vida em torno da } \\
\text { prática permanente de } \\
\text { mochileiro (viajantes } \\
\text { como estilo de vida) }\end{array}$ & $\begin{array}{l}\text { Consumo de } \\
\text { estilo de vida, } \\
\text { mochileiro, } \\
\text { mobilidade, } \\
\text { indeciso, } \\
\text { identidade. }\end{array}$ & $\begin{array}{l}\text { Estudo etnográfico. } \\
\text { Foram entrevistados } \\
25 \text { viajantes no norte } \\
\text { da Índia e sul da } \\
\text { Tailândia. }\end{array}$ & $\begin{array}{l}\text { A partir da construção de } \\
\text { viajante, que (re)constitui } \\
\text { essa identidade como } \\
\text { socialmente desviantes, o } \\
\text { conceito de estilo de vida } \\
\text { permite uma avaliação } \\
\text { contemporânea dos padrões } \\
\text { de consumo significativos, } \\
\text { perspectivas desses } \\
\text { indivíduos, mais amplas } \\
\text { desses indivíduos em como } \\
\text { a mobilidade contínua pode } \\
\text { levar a diferentes formas de } \\
\text { compreensão das identidades } \\
\text { e relativas ao lugar. }\end{array}$ \\
\hline
\end{tabular}

Dentre os estudos selecionados, todos são de periódicos internacionais: International Review for the Sociology of Sport, Journal of Adolescence, Social Science \& medicine, Child Development, Humboldt Journal of Social Relations, Journal of Urban Design, Leisure Studies, Tourism Management, Journal of Leisure Research, Journal of Quantitative Criminology, Adolescence, Developmental Psychology, Annals of Tourism Research, Cyberpsychology \& Behavior, Drug and Alcohol Dependence, Évfolyam, Northeastern Recreation Research Symposium Preventive Medicine e International Journal of Drug Policy. Das bases de dados selecionadas, não foram encontrados artigos originais referentes à temática no Brasil.

Referente aos objetivos de estudo dos artigos selecionados, observamos três temáticas centrais: 1) adolescente no contexto da rotina, esporte, lazer, substância psicoativa e 
relação entre os pais, além do uso de forma recreativa por adultos; 2) trabalho no âmbito da produção de maconha, no trabalho das mulheres e na utilização de substâncias psicoativas; 3) comportamento desviante em parques, no turismo e no excesso da utilização de internet. Os estudos foram desenvolvidos a partir de diversos procedimentos metodológicos. Contudo o estudo com survey, representado por 6 artigos, foi o mais utilizado, seguido pela pesquisa transversal, com 5 artigos, pela pesquisa longitudinal com 3 e a etnográfica com 2 estudos. Outros procedimentos encontrados foram: pesquisa exploratória, estudo quase-experimental pesquisa narrativa, grounded theory e método misto.

A diversidade de estudos encontrados referente às práticas corporais e ao comportamento desviante evidenciou a importância desta temática por meio de diferentes grupos e práticas. Assim, de acordo com as temáticas centrais elaborou-se três categorias analíticas, construídas a posteriori, baseada na proposta que os autores trataram as temáticas abordadas nos estudos: a primeira, "lazer, práticas corporais e comportamento desviante em adolescentes e adultos", integra 12 estudos que envolvem diferentes países, a segunda, "práticas corporais e comportamento desviante no âmbito do trabalho", contendo 3 artigos os quais consistem a produção e utilização de substâncias psicoativas, e a terceira, "práticas corporais e comportamento desviante em diferentes grupos", composta por 5 estudos de situações diversificadas.

\section{Lazer, Práticas corporais e comportamento desviante em adolescentes e adultos}

Esta categoria de análise é composta por 12 estudos que retratam a questão dos adolescentes no contexto desviante, as atividades de esporte e lazer e relacionamento entre pais e amigos. Desta forma, inicia-se a discussão ressaltando a aceitação do esporte para crianças e adolescentes como contribuição educacional e de desenvolvimento no âmbito positivo (HALLDORSSON. THORLINDSSON; SIGFUSDOTTIR, 2014). Contudo, os autores apontam que investigações sobre a temática mostram resultados mistos, apontando seus aspectos positivos, mas também negativos, pois as práticas corporais são organizadas em diferentes contextos sociais, ressaltando entre estes, os problemas sociais.

O estudo de Thorlindsson, Vilhjalmsson e Valgeirsson (1990) já apontava para tais problemas entre a prática corporal vinculada ao fumo e ao álcool. Nessa direção, Peretti-walter e Lorente (2004) analisaram a relação do uso da maconha e as práticas corporais na França e concluíram que o envolvimento em atividades formais está menos associado ao consumo regular da maconha quando comparado a práticas corporais informais. Este resultado corrobora estudos já realizados por Mahoney e Stattin (2000), os quais defendem que as práticas altamente estruturadas para os adolescentes correspondem a níveis baixos de condutas antissociais. Resultados semelhantes foram encontrados no estudo de Trainor et al. (2010), realizado com adolescentes no sul da Austrália, em que práticas corporais menos estruturadas foram associadas ao uso de substâncias psicoativas.

Nessa direção, o estudo de Doktor-Jelölt (2013), ressaltou que os jovens estão mais envolvidos com práticas corporais regulares são mais conscientes com a saúde e menos 
propícios ao consumo de substâncias psicoativas. O autor aponta que os jovens estão cada vez mais inativos, e dispõe-se a assistir mais televisão, ler menos, o que pode conduzir a comportamento desviante. Os estudos de Thorlindsson e Bernburg (2006), também encontraram que o comportamento desviante nos adolescentes vai depender do tipo de padrão de lazer que os adolescentes estão envolvidos. Além disso, as práticas corporais, planejada e direcionada como forma de precaução, podem funcionar como agentes de prevenção ao uso de álcool e drogas, mesmo que os praticantes estejam em contato próximo a colegas que fazem uso dessas substâncias. Contudo, estes resultados só estão assegurados quando a prática corporal vem relacionada a outros fatores como a família e a escola.

Nesse contexto, a família tem uma relação fundamental no comportamento desviante dos adolescentes. O estudo de Vazsonyi et al. (2002) revela que os adolescentes que gastam mais tempo com a família foram negativamente associados ao comportamento desviante. Por outro lado, o estudo de Keijsers et al. (2012) aponta que a proibição de amizade, pelos pais que julgam o relacionamento, pode influenciar positivamente no comportamento desviante e a inadimplência de adolescentes. No mesmo contexto, Frijns et al. (2010) apontam que a associação de divulgação e sigilo no relacionamento entre pais e adolescentes são dois fatores relacionados a medida de externalização e internalização dos problemas existentes. De acordo com os autores, o sigilo é um preditor da depressão e delinquência. O sigilo dos pais pode direcionar a delinquência desde cedo na adolescência (FRIJNS, et al., 2010).

A pesquisa de Kristjansson et al. (2010) sobre o uso de substância em adolescentes e monitoramento dos pais nas práticas corporais, realizada na Islândia, revelou que o monitoramento parental e a participação dos adolescentes nas práticas corporais organizadas aumentou nas comunidades que adotaram programas de intervenção, e diminuiu o uso do álcool, quando comparada as comunidades que não estruturaram práticas corporais, e os adolescentes ficam com mais tempo ocioso. Para Measham (2004), os espaços estruturados para o lazer também são significantes para o controle do uso de álcool e drogas. Vale destacar a importância do sujeito buscar autonomia quanto as escolhas de organização do tempo livre, pois a estruturação do tempo, não significa que o sujeito está imune ao comportamento desviante.

Referente ao estudo de Titzmann, Silbereisen e Mesch (2014) realizado com imigrantes da diáspora étnica alemã, da antiga União Soviética e nativos alemães, aponta que os adolescentes de etnia alemã apresentaram níveis iniciais de delinquência superiores aos dos adolescentes nativos da Alemanha e níveis inferiores aos dos adolescentes judeus russos. Além disso, o estudo revelou que adolescentes alemães étnicos relataram níveis iniciais de inadimplência mais elevados do que os nativos, contudo não foi possível explicar as diferenças étnicas e níveis de inadimplência.

Em relação ao uso de drogas ilícitas por adultos como prática no contexto do lazer foram encontrados três pesquisas. Dois estudos (LIEBREGR et al., 2015; ASKEW, 2016), relacionaram o uso da maconha, sejam dependente ou não, de forma recreacional. $\mathrm{O}$ uso da maconha no contexto do lazer, é caracterizado como um elemento cultural e faz parte do cotidiano de usuários e não usuários. Nesses estudos, os usuários de maconha dizem 
apresentar uma vida convencional, incluindo, por exemplo, as obrigações profissionais e vida social. Vale frisar o debate sobre os benefícios de seus princípios ativos para a saúde ou tratamento de doenças em termos do uso medicinal e também recreativo. Além disso, as escolhas para o uso recreacional, estão baseadas no julgamento dos aspectos culturais, moral e legal de uma determinada sociedade (KONOPKA, 2014).

Em suma, a participação dos pais na vida dos adolescentes torna-se importante, bem como no acompanhamento de práticas corporais estruturadas, visando um sentido de prevenção ao comportamento desviante e o uso de álcool e drogas. Torna-se evidente que essas características não são unicamente estratégias de prevenção a esse tipo de conduta, mas contribui para a formação e prevenção dos adolescentes. Por outro lado, quando se analisa o consumo de substâncias psicoativas por adultos, não se faz relação a comportamentos delinquentes.

\section{Práticas corporais e comportamento desviante no âmbito do trabalho}

Esta categoria de análise contém três artigos que discute a dimensão do trabalho envolvendo três situações diferentes: o trabalho e a produção da maconha, o trabalho e o consumo de drogas ilícitas e profissionais que trabalham com a reabilitação de dependente de álcool, drogas e jogos. Nesse aspecto, são três âmbitos isolados que o trabalho torna centralidade, dois em um sentido desviante, e um, o qual busca rrabilitação de usuários, traz um retorno negativo no que diz respeito à saúde do trabalhador.

O primeiro ponto a ser discutido foi o estudo de Boylstein (2013) que trata sobre o cultivo da maconha como carreira desviante e lazer sério4, e analisou uma rede social de plantadores de maconha na Flórida Central e do Norte. Esta rede foi formada por homens e mulheres com pelo menos 1 diploma universitário que trabalham legalmente como professor ou empresário, por exemplo. A produção da maconha, incluindo técnicas para maximizar sabor e produção, são desenvolvidas principalmente para o uso pessoal e gozo. Contudo, o estudo aponta que há também casos de interrupção da rede, quando algum produtor sai da carreira desviante influenciada pelo risco de detecção, compromisso com família ou ocupação convencional. Caulikins e Pacula (2006) apontam que essas redes sociais de produção de maconha geralmente são realizadas entre amigos e parentes para não serem dominados pelo mercado de vendedores profissionais, quando o risco se torna maior.

Inciardi (1975) destaca que a carreira profissional no crime distingue do criminoso de carreira pelo grau de compromisso com o trabalho. O compromisso com as normas desviantes adota padrões de comportamento encontrados no meio de uma determinada rede social. Assim, Boylstein (2013) coloca que o nível de compromisso na carreira de um usuário é adquirido a partir de um processo de socialização na rede, neste pensar, Becker (2008) ressalta que o usuário passa por um processo de aprendizagem, para poder

4 Lazer sério: prática sistematizada de uma determinada atividade por amador, voluntária, com base substancial, que permite uma carreira centrada no conhecimento, experiência e habilidade (STEBBINS, 2001). 
participar de uma subcultura organizada acerca de uma atividade desviante. É importante frisar que o problema do diagnóstico "desviante" tem efeitos sociais, políticos e econômicos negativo na vida de sujeitos e grupos classificados como minorias étnicas.

Outro fato da relação de trabalho e uso de álcool e de droga ilícita foi estudado por Belhassen e Shani (2013), em que apontaram trabalhadores de uma rede hoteleira em Israel, formada por jovens com baixo nível educacional e recebendo baixos salários, o que tornava uma alta rotatividade de trabalho. Esses trabalhadores apresentaram um consumo de álcool considerável, aproximadamente 45,7\%, de uma amostra de 473 participantes que estiveram envolvidos com álcool, e 13,8\% utilizava a maconha ou haxixe. Já a pesquisa de Frone (2008) estudou trabalhadores norte-americanos e encontrou a relação entre estressores de trabalho para o uso do álcool e drogas ilícitas. Além disso, o uso do álcool e de drogas ilícitas muitas vezes é utilizado para estender o horário de trabalho. Frone (2006) ressalta que o consumo de álcool e de drogas ilícitas no local de trabalho envolve aproximadamente 15,3\% e 3,1\% de trabalhadores nos Estados Unidos, respectivamente. O consumo dessas substâncias psicoativas geralmente está associado à diminuição de tensão no trabalho o que pode conduzir a dependência química.

Ainda relacionado ao trabalho e consumo de álcool e drogas ilícitas, incluído aqui também, a dependência do jogo, o estudo de Wood e Tirone (2013), analisou o lazer das mulheres cuidadoras de usuários dependentes. Essas cuidadoras obtiveram descrições de ansiedade, estresse, preocupação, raiva, depressão, sentimento de culpa, perda e abuso emocional, verbal e física, o que prejudica diretamente na saúde das mulheres cuidadoras.

Referente ao lazer os autores supracitados encontraram três aspectos distintos: a primeira, a perda da prática de lazer, em consequência da falta de energia mental, recursos necessário e/ou limitação financeira impedir a vivência na prática do lazer; a segunda, a negociação do lazer, foi relatado pelas cuidadoras a necessidade de um tempo mínimo para realizar alguma atividade como artesanato, ouvir música ou caminhada próximo a residência; e a terceira, a prática de lazer como forma de fuga, estratégia utilizada pelas cuidadoras que relataram como forma de distração do trauma, e minimizar o sentimento de responsabilidade de cuidar do outro. Armstrong e Armstrong (2001) ressaltam que o cuidar é uma atividade complexa e compartilhada, desta forma envolve normas construídas pela situação que influencia o cuidador a gastar seu tempo livre, prejudicando a sua saúde em consequência da tensão do ato de cuidar e os demais problemas relacionados.

\section{Práticas corporais e comportamento desviante em diferentes grupos}

Esta categoria de análise constitui-se de 5 artigos que tratam das práticas corporais e comportamento desviante em diferentes contextos, focando o turismo, os parques e por último a internet. O primeiro aspecto a ser discutido é acerca do turismo com o estudo de Cohen (2011) que trata sobre o mochileiro como opção de estilo de vida. Esses mochileiros, considerados andarilhos, constituem sua identidade social como desviante, pois há uma avaliação contemporânea dos padrões existentes na sociedade relacionados, como 
exemplo, aos significados, ao consumo e as formas de mobilidade. Os autores apontam que a rotulagem desses viajantes representa um desvio social com base na regressividade relacionada à produção e ao consumo. Além disso, esse estilo de vida optado pelos viajantes é uma decisão de livre escolha que conduz a significados e a construção de identidades por meio desse estilo de vida (COHEN; DUNCAN; THULEMARK, 2014).

Estes viajantes não apresentam relações com os lugares que visitam, o que torna necessário viajar para outros lugares, o que caracterizam como desviantes. O estudo de Anderson e Erskine (2014) ressaltam a necessidade de viajantes quando não há uma relação com o lugar. Os viajantes que tem este parâmetro como estilo de vida procuram dinamismo, mudanças e instabilidades, considerados como topofilia (ANDERSON; ERSKINE, 2014). Por outro lado, os autores frisam a necessidade da relação pessoa-lugar, o que caracteriza a tropofilia, embora isso só ocorre quando coincidem positivamente a conexão entre pessoa e lugar.

Outro aspecto desviante sobre o turismo é o uso da maconha, estudado por Belhassen, Santos e Uriely (2007). O motivo dos viajantes que usam maconha vai de acordo com o significado que estes atribuem às experiências com a maconha durante a viagem, destacando quatro aspectos centrais: a experimentação, a busca pelo prazer, busca de autenticidade e o consumo. Estas características são condizentes da natureza e experiências dos participantes do estudo. O uso de drogas, como a maconha, para Uriely e Balhassen $(2005 ; 2006)$, está relacionada com a quantidade ou tipo de risco que o turista está interessado em experimentar, pois se caracteriza como um comportamento desviante, em que o turista tenta desprender-se da vida normal, de forma que encontre experiências significativas, que envolve o turista e a cultura de um local.

A segunda questão a ser tratada neste tópico é a relação dos equipamentos de lazer com o comportamento desviante. Taylor e Khan (2011) estudaram os usos das pistas de skate na Austrália Ocidental e assinalaram que os skatistas acreditam que os adultos os veem como sendo antissociais e desviantes, sendo o skate um passatempo indesejável. Os parques para skates são designados geralmente para jovens, que são rotulados por equívoco, pois esses jovens encontraram na prática do skate benefícios relacionados à saúde física, e de socialização entre os praticantes (DUMAS; LAFOREST, 2009).

Outro ponto relacionado ao comportamento desviante em parque está associado à invasão urbana nas áreas de recreação apresentado por Wynveen, Bixler e Hammitt (2006). Com essa invasão urbana vem à percepção de comportamentos desviantes como exemplo o crime, que vem ocorrendo com frequência envolvendo roubos, incêndio, homicídios e vandalismo. Os autores relacionam a invasão urbana com a percepção de crimes. Contudo, Dunham e Alpert (1997) ressaltam que o crime no parque não é relacionado à experiência recreativa dos sujeitos.

O último aspecto a ser discutido nesse tópico é a questão do uso da internet como comportamento desviante, estudado por Engelberg e Sjöberg (2004). O excesso na utilização da internet está relacionado à solidão, a adesão de valores idiossincráticos e à inteligência emocional. Os autores apontam que a solidão favorece o desencadeamento de atitudes desviantes, uma vez que a internet foi pensada para interligar pessoas e, assim, seu uso 
frequente sem interação social seria um uso não-convencional. Pontes, Griffiths e Patrão (2014) desenvolveram uma pesquisa com crianças e adolescentes em Portugal sobre o uso compulsivo de internet. Particularmente quando associado à solidão, o abuso do meio virtual conduz a problemas comportamentais e afeta negativamente o bem-estar psicológico.

Considerando estes aspectos em diferentes grupos a partir dos sentidos negativos, percebe-se que há problemas nos mais diversos âmbitos seja individual, como exemplo a saúde física e psíquica, até mesmo relacionados aos problemas sociais, como a violência e a segurança pública. O constante crescimento do comportamento desviante, precisar ser analisada, de forma coletiva, e também, isolada a fim de compreender e traçar soluções referentes às questões necessárias para cada caso específico. Destaca-se que o estudo apresenta limitações. É importante que o viés de publicação seja revisado, pois pesquisas com resultados positivos tem mais chances de serem publicados, quando comparados aos que encontram resultados negativos.

\section{CONSIDERAÇÕES FINAIS}

Os achados que predominaram no estudo e merecem atenção, foram questões sobre o envolvimento de adolescentes com o consumo de álcool e drogas e outros comportamentos desviantes. Além disso, foram encontrados estudos que apontam substâncias psicoativas como meio de trabalho, como por exemplo, plantações, e também relacionadas a permanência no local de trabalho de forma mais ativa.

Em outra direção, as práticas corporais se mostraram efetivas como aspecto que podem auxiliar na prevenção de uso de álcool e drogas, mas que sejam direcionadas as formas de prevenção. Quando não elas podem ser um fator de vulnerabilidade. Deste modo, as práticas corporais precisam ser trabalhadas como um fator educacional, para que possa auxiliar na busca de mudanças do estilo de vida de um sujeito desviante.

Não foram encontrados estudos dessa natureza no Brasil. Portanto, sugerimos novas pesquisas, a partir do desenvolvimento de estudos originais, a fim de investigar as práticas corporais como formas de prevenção para o comportamento desviante, contribuindo para o avanço da temática.

\section{REFERÊNCIAS}

AHN C.W. et al. A study on the development of the protocol of leisure activity program for the elderly's deviant prevention. Journal of Exercise Rehabilitation, Incheon/Korea, v. 10, n. 2, p. 106-110, 2014.

ANDERSON, J.; ERSKINE, K. Tropophilia: a study of people, place and lifestyle travel. Mobilities, UK, v. 9, n. 1, p. 130-145, 2014.

ARMSTRONG, P.; ARMSTRONG, H. Thinking it through: Women, work and caringin the new millennium. Halifax, NS: Healthy Balance Research Program, 2001. 
ASKEW, R. Funcional fun: ungarians adult recreational drug use. International Journal of Drug Policy, v. 36, p. 112-119, 2016.

BARDIN, L. Análise de conteúdo. Tradução. Luís Antero Reto e Augusto Pinheiro. Lisboa: Edições 70, 2002.

BECKER, H. S. Outsiders: estudos de sociologia do desvio. Rio de Janeiro: Jorge Zahar Ed., 2008.

BELHASSEN, Y. SHANI, A. Substance abuse and job attitude among hotel workers: social labeling perspectives. Tourism Management, Hamilton/NZ, v. 34, p. 47-49, 2013.

BELHASSEN, Y; SANTOS, C. A.; URIELY, N. Cannabis usage in tourism: a sociological persoective. Leisure Studies, UK, v. 23, n. 3, p. 303-319, 2007.

BOURDIEU, P. Gostos de classe e estilo de vida. In: ORTIZ, R. A sociologia de Pierre Bourdieu. São Paulo: Editora Olho D'água, 2013.

BOYLSTEIN, C. Small-scale marijuana growing: deviant careers as seriou leisure. Humboldt Journal of Social Relations, Arcata/CA v. 35, p. 52-70, 2013.

BRASIL. Ministério do Esporte. Diretrizes do Programa Segundo Tempo. 2011.

CAULKINS, J. P.; PACULA, R. L. Marijuana markets: Inferences from reports by the household population. Journal of Drug Issues, Florida State, v. 36, n. 1, p.173-200, 2006.

COELHO, Celenita; PEREZ-RAMOS, Aidyl M. de Queiroz. Abstinência e a redução de danos no processo de recuperação dos dependentes de substâncias psicoativas. Boletim - Academia Paulista de Psicologia [online]. São Paulo/SP, v.28, n.1, p. 79-86, 2008. Disponível em: < http://pepsic.bvsalud.org/scielo.php?pid=S1415711X2008000100010\&script =sci_arttext> Acesso em: 05 mai. 2017.

COHEN, S. A. Lifestyle ungarian backpacking as a way of life. Annals of Tourism Research, Guildford/UK, v. 38, n. 4, p. 1535-1555, 2011.

COHEN, S. A.; DUNCAN, T.; THULEMARK, M. Introducing lifestyle mobilities. In: DUNCAN, T.; COHEN, S. A.; THULEMARK, M. Lifestyle Mobilities: intersections of travel, leisure and Migration, 2014.

DOKTOR-JETÖLT, T. B. A szabadiős tevékenység változása 15.18 éves magyarországi fiatalok körében: fizikai aktivitás, médiafogyasztás és dohányzás. Évfolyam, Magyarország, v. 15, p. 581-589, 2013.

DUNHAM, R.; ALPERT, G .P. Critical issues in policing: contemporary readings. 4. Ed. Prospect Heights, IL: Waveland Press, Inc., 1997.

DUMAS, A.; LAFOREST, S. Skate-parks as a health-resource: are they as dangerous as they look? Leisure Studies, UK, v. 28, n. 1, p. 19-34, 2009.

ELIAS, N.; SCOTSON, J. L. Os estabelecidos e os outsiders: sociologia das relações de poder a partir de uma pequena comunidade. Rio de Janeiro: Jorge Zahar Ed., 2000.

ENGELBERG, E.; SJÖBERG, L. Internet use, social skills, and adjustment. CyberPsychology \& Behavior, San Diego, CA v. 7, n. 1, p. 41-47, 2004.

FRIJNS, T. et al. What parents don't know and how may affect their children: qualifying the disclosure-adjustment link. Journal of Adolescence, Oberlin/USA, v. 33, p. 261$270,2010$. 
maio/2018

FRONE, M. R. Prevalence and distribution of alcohol use and impairment in the workplace: A U.S. national survey. Journal of Studies on Alcohol, USA, v. 67, n. 1, 147-156, 2006.

FRONE, M. R. Are work stressors related to employee substante use? The importance of temporal ungari in assessment of alcohol and illicit drug use. Journal of Applied Psychology, Maryland/USA, v. 93, n. 1, 199-206, 2008.

GOMES, I. S.; CAMINHA, I. O. Guia para estudos de revisão sistemática: uma opção metodológica para as Ciências do Movimento Humano. Movimento, Porto Alegre/ RS, v. 20, n. 1, p. 395-411, 2014.

HALLDORSSON, V.; THORLINDSSON, T.; SIGFUSDOTTIR, I. D. Adolescent sport participation and alcohol use: the importance of sport organization and the wider social context. International Review for the Sociology of Sport, USA, v. 49, n. 3/4, p. 311-330, 2014.

INCIARDI, J. A. (1975). Careers in crime. Chicago, IL: Rand McNally, 1975.

IWASAKI, Y.; COYLE, C.; SHANK, J. W. Leisure as a context for active living, recovery, health and life quality for persons with mental illness. Health Promotion International, Australia, v. 25, n. 4, p. 483-494, 2010.

KEIJSERS L. et al. Forbidden friends as forbidden fruit: parental supervision of friendships, contact with deviant peer, and adolescent delinquency. Child Development, Malden/ USA, v. 83, n., 2, p. 651-666, 2012.

KONOPKA, L. M. Marijuana use: neuroscience perspective. Croatian Medical Journal, v. 55, n. 3, 2014.

KORHONEN et al. Physical activity in adolescence as a predicator of alcohol and ungari drug use in early adulthood: a longitudinal population-based twin study. Twin Research and Human Genetics, Brisbane/Australia, v. 12, n. 3, p. 261-268, 2009.

KRISTJANSSON, A. L. et al. Adolescent substance use, parental monitoring, and leisuretime activities: 12-year outcome of primary prevention in Iceland. Preventive Medicine, Montreal/ Canada, n. 51, p. 168-171, 2010.

LIEBREGTS, N. et al. The role of leisure and delinquency in frequent cannabis use and dependence trajectories among young adults. International Journal Policy, v. 26, n.2, p. 143-152, 2015.

MAHONEY, J. L.; STATTIN, H. Leisure activities and adolescent ungarian behavior: the role of structure and social context. Journal of Adolescence, Oberlin/USA, v. 23, n. 2, p. 113-127, 2000.

MEASHAM, F. Play space: historical and socio-cultural reflections on drug, licensed leisure locations, commercialization and control. International Journal of Drug Policy, London/ UK, n. 15, p. 337-345, 2004.

MULROW, C. D. Systematic reviews: rationale for systematic reviews. BMJ, London/UK, 309, p. 597-599, 1994.

PALMA, A.; ABREU, R. A.; CUNHA, C. A. Comportamentos de risco e vulnerabilidade entre estudantes de educação física. Revista Brasileira de epidemiologia, São Paulo/ SP, v. 10, n. 1, p. 117-126, 2007.

PERETTI-WATEL, P. How does one become a cannabis smoker? A quantitative perspective.

Revue Française de Sociologie, France, v. 44 p., 3-27, 2003. 
PERETTI-WATEL, P.; LORENTE, F. O. Cannabis use, sport practice and other leisure activities at the end of adolescence. Drug and Alcohol Dependence, Maryland/USA, v.73, n. 3, p. 251-257, 2004.

PONTES, H. M.; GRIFFITHS, M. D.; PATRÃO, I. M. Internet addiction and loneliness among children and ungarians in the education setting: na empirical pilot study. Ciències de L'Educació I de L'Esport, France, v. 32, n. 1, 2014.

ROMERA, L. A. Copa do Mundo e cerveja: impactos intangíveis de um megaevento. Movimento, Porto AlegreRS, v. 20, n. 2, p.775-798, 2014.

ROMERA, L. A. Esporte, lazer e prevenção ao uso de drogas: dos discussos equivocado aos caminhos possíveis. Licere, Belo Horizonte/MG, v. 16, n.4, p. 1-20, Belo Horizonte, 2013.

ROMERA, L. A.; REIS, H. H. B. Uso de álcool, futebol e torcedores jovens. Motriz, Rio Claro/ SP, v. 15, n. 3, p. 541-551, 2009.

ROMERO, L. R. Consumo de drogas e níveis e atividade física entre estudantes de ensino fundamental e médio de cidade do interior Paulista. Dissertação (Mestrado) - Faculdade de Medicina Botucatu, Universidade Estadual Paulista, 2006.

STEBBINS, R. A. Serious leisure. Society, Wellesley/MA, v. 39, n. 4, p. 53-57, 2001.

TAYLOR, M.. KHAN, U. Skate-park builds, teenaphobia and the adolescent need for hangout spaces: the social utility and functionality of urban skate parks. Journal of Urban Design, London/UK, v. 16, n. 4, p. 489-510, 2011.

THORLINDSSON, T.; BERNBURG, J. G. Peer groups and substance use: ungarian the direct and interactive effect of leisure activity. Adolescence, Oberlin/USA, v. 41, n. 162, p. 321-340, 2006.

THORLINDSSON, T.; VILHJALMSSON, R.; VALGEIRSSON, G. Sport participation and perceived health status: a study of adolescents. Social Science \& Medicine, Boston/ USA, v. 31, n. 5, p. 551-556, 1990.

TITZMANN, P. F.; SILBEREISEN, R. K.; MESCH, G. Minor delinquency and immigration: a longitudinal study among male adolescents. American Psychological Association, Worcester/USA, v. 50, n. 1, p. 271-282, 2014.

TRAINOR, S. Leisure activities and adolescent psychological well-being. Journal of Adolescence, Oberlin/USA n. 33, p. 173-186, 2010.

URIELY, N. BALHASSEN, Y. Drugs and tourists' experiences. Journal of Travel Research, Colorado/USA, v. 43, n. 3, p. 238-246, 2005.

URIELY, N. BALHASSEN, Y. Drugs and risk-taking in tourism. Annals of Tourism, Guildford/ UK, v. 33, n. 2, p. 339-359, 2006.

VAZSONYI, A. et al. Routine Activities and deviant behaviors: ungaria, dutch, ungarian, and Swiss youth. Journal of Quantitative Criminology, UK, v. 18, n. 4, p. 397- 422, 2002. WANDERLEY, F. Normalidade e patologia em educação especial. Psicologia: Ciência e Profissão, v. 19, n.2, 1999.

WOOD, S.; TIRONE, S. The leisure of women caring for people harmfully involves with alcohol, drug, and gambling. Journal of Leisure Research, Minnesota/USA, v. 45, n. 5, p. 583-601, 2013. 
maio/2018

WRIGHT, R. W.; BRAND, R. A.; DUNN, W.; SPINDLER, K. P. Howtowrite a systematic review. Clinical Orthopaedics and related research, New York: Springer, n.455, p. 23-29, 2007. Doi: 10.1097/BLO.0b013e31802c9098 . Disponível em: <http:// www.ncbi.nlm.nih.gov/pubmed/17279036> .

WYNVEEN, C. J.; BIXLER, R.; HAMMITT, W. E. Urban encroachment brings deviant behavior to resource recreation areas. Northeastern Recreation Research Symposium, Maryland/USA, v. 14, p. 566-572, 2006.

$\mathrm{YI}, \mathrm{ES}$. The relationship between the participant's level of gateball activity and leisure attitude of the aged. Korean Journal Social Sport, Korean, v.18, n. 1, p. 135-149, 2005.

Recebido em: Fevereiro/2017 Aprovado em: Julho/2017 